\title{
Left Lung, Inferior Lobe, Anterior Basal Segment
}

National Cancer Institute

\section{Source}

National Cancer Institute. Left Lung, Inferior Lobe, Anterior Basal Segment. NCI

Thesaurus. Code C132393.

The anterior basal segment of the inferior lobe of the left lung. 